\title{
Gender Norms and Discourses Informing College Men's Perceptions of Heteronormative Sexual Health Responsibilities and HPV Prevention
}

\author{
Samantha J. Stanley ${ }^{1}$, Sara Kim² ${ }^{2}$ and Margaret Jane Pitts ${ }^{2}$ \\ Department of Communication \\ ${ }^{1}$ University of Maryland \\ ${ }^{2}$ University of Arizona \\ Author Note
}

\begin{abstract}
Samantha J. Stanley, Department of Communication, University of Maryland; Sara Kim, Department of Communication, University of Arizona; Margaret Jane Pitts, Department of Communication, University of Arizona.

This study was supported with a small grant awarded to the third author from the Social and Behavioral Sciences Research Institute of the College of Social and Behavioral Sciences at the University of Arizona. A version of this manuscript has been submitted for presentation at the $1^{\text {st }}$ International Symposium on Intergroup Communication to be held in Thessaloniki, Greece in June, 2017. We thank Drew Miller, Karla Cota, and Frank Meza for their assistance with data collection and management.

Correspondence concerning this article should be addressed to Samantha J. Stanley, Department of Communication, 2130 Skinner Building, University of Maryland, College Park, MD 20742. Email: sjstan@umd.edu
\end{abstract}

Keywords: college men, norms, gender discourse, self-categorization, sexual health, HPV 


\begin{abstract}
Focus group data revealed that despite reporting expectations for high sexual activity, college men were ambivalent about sexual health responsibility and their role in preventing human papillomavirus (HPV). Participants identified shared sexual health responsibility as an ideal, but invoked normative gender discourses to rationalize inequality in partnered sexual health. Selfcategorization processes based on gender may prevent college males from engaging self- and partnered protective behaviors. Yet, self-categorization processes also enabled college men to envision a future relational identity as husband and father in which they engaged protective sexual health behaviors. Implications for self-categorization processes in HPV prevention are discussed.
\end{abstract}




\section{Gender Norms and Discourses Informing College Men's Perceptions of Heteronormative Sexual Health Responsibilities and HPV Prevention}

In partnered health contexts, like sexual relationships, health behavior likely varies based on how people categorize themselves and their partners. When people socially categorize, their group identity becomes salient and they act according to perceived group norms (Hogg \& Turner, 1987). In the case of sexual health, social categorization along gender lines likely emerges as salient and may disproportionately affect behaviors such as the prevention of human papillomavirus (HPV). Indeed, in a larger study about college male HPV prevention (Authors, 2016) social categorization seemed to occur among college men who used gender norms in order to explain their own role in sexual health responsibility.

In this analysis, we explore male participants’ perceived group norms informed by gender discourses that rationalize unequal sexual health responsibilities for men and women. It is important to note that most participants in this study identified as heterosexual cisgender males and therefore their discourse largely reflects that viewpoint. While this limits the diversity of discourses represented, given the heteronormativity on college campuses (see Tetreault, Fette, Meidlinger, \& Hope, 2013; Wickens \& Sandlin, 2010), male underrepresentation in HPV prevention (Malkowski, 2014; Thompson, 2010), and heterosexual males’ lower general HPV awareness compared to gay and bisexual men (Gilbert, Brewer, Reiter, Ng, \& Smith, 2011), we believe that in this case such a focus is appropriate. Participants' perceived norms not only create disparity in perceptions of sexual health responsibility, but also influence preventative behaviors, including the prevention of HPV. HPV is a highly prevalent sexually transmitted disease (STD) with potential for severe long-term consequences for men and women many of which can be prevented with vaccination (Centers for Disease Control and Prevention [CDC], 2016a). Our 
findings have implications for future health messages about partnered health, including HPV prevention.

\section{Background}

Social categorization and social identity are important factors in health behavior (see Haslam, Jetten, Postmes, \& Haslam, 2009). Social identities may be particularly important in partnered health behaviors, like sexual relationships, because of a media and health climate where the broader discourse encourages social categorization by gender (Heather \& Murphy, 2010). Discourse is defined here as a "shared set of concepts, categories, and ideas that provide its adherents with a framework for making sense of situations, embodying judgments, and fostering capabilities” (Dryzek, 2006, p. 8). Heterosexual gender discourse is rooted in an ideology of femininity that assigns women the traits of "being responsive and caring, preserving relationships, curbing hunger (for food and sex), and not expressing sexuality” and an ideology of masculinity that assigns men the traits of "protecting and providing for female others ... and having irrepressible sexual desire for women” (Tolman, Davis, \& Bowman, 2016, p. 5).

Femininity and masculinity ideologies are reproduced and reified in media and health institutions. Media targeting early adolescents perpetuate gender ideologies by portraying girls as responsible for teen pregnancy, STD prevention, and contraception, and boys as obsessed with sex and sexual performance (Hust, Brown, \& L’Engle, 2008). The portrayal of women as gatekeepers of sexual health is reinforced with medical recommendations that women begin regular gynecological exams at age 21 while men are prescribed no equivalent sexual health exams (Thompson, 2010). Even on college campuses, including the one where this study took place, student health services frequently offer women’s sexual health clinics but no equivalent clinic for men. This lack of equivalently focused health care is not unusual; men are rarely part 
of health promotion discourse (Courtenay, 2000). Courtenay (1998) recognized this discrepancy almost two decades ago when he noted research on the impact of gender identity on men's health practices had been neglected. Gender discourses are especially relevant in HPV prevention.

\section{Male and Female Roles in HPV Prevention}

HPV is the most common STD with almost all sexually active men and women infected at some point in their lifetime (CDC, 2016a). HPV infection can have serious consequences for both men and women, including genital lesions, anogenital and oral cancers in men, and cervical cancer in women (Palefsky, 2010). In 2006, the Food and Drug Administration (FDA) approved a vaccine that prevents the most harmful strains of HPV for women aged 9-26 and then in 2009 approved the same vaccine for men aged 9-26 (CDC, 2011a). While female vaccination rates jumped immediately after approval (21.5\% of girls ages $13-17$ had received at least one dose of the vaccine one year post vaccine approval), the percentage of boys ages 13-17 who received even one dose of the vaccine was $1.4 \%$ one year post vaccine approval and remains low (CDC, 2011b). As of 2015, only $49.8 \%$ of men ages $13-17$ had received at least one dose of the vaccine compared to $62.8 \%$ of equivalent women, and only $28.1 \%$ of men had completed the vaccine series compared to $41.9 \%$ of women (CDC, 2016b). The low vaccination rates for men are especially distressing given that men are the primary vectors for the transmission of HPV (Reiter, Pendergraft, \& Brewer, 2010).

The discrepant rates of HPV vaccination may be exacerbated by a health and media climate that historically framed HPV as a “women’s-only health issue” despite a body of medical research pointing to the role of men in HPV transmission (Malkowski, 2014). The pharmaceutical company that manufactures the HPV vaccine Gardasil narrativized HPV as a women's health issue even before the vaccine was approved with a national awareness campaign 
linking HPV to cervical cancer (Malkowski, 2014). Messages framing HPV as a women’s health issue gained greater amplitude through magazines, newspapers, and insurance companies that promoted the vaccine for women yet ignored the role of men (Thompson, 2010). Messages such as these may detract males from HPV prevention due to misperceptions that HPV is a womenonly issue (Authors, 2016). Even at the FDA priority hearing on HPV vaccination gender discourses likely disproportionally affected the decision to release the vaccine for women only first (Thompson, 2010). Indeed, the delayed approval and recommendation for men occurred despite the urging of pharmaceutical scientists to include men in HPV vaccination (Thompson, 2010). The FDA did not approve the HPV vaccine for men until 2009 and the Advisory Committee on Immunization Practices did not recommend routine male HPV vaccination until 2011 (CDC, 2011a).

We believe that HPV, like other sexual health issues, should be considered from a partnered health perspective. Unfortunately, echoes of gender discourse in health contexts likely induce social categorization when partnered health is at stake. When sexual partners socially categorize by gender, gender norms and discourses that assign responsibility for sexual health to women and limit men from taking full responsibility as sexual partners are likely to gain more relevance in behavioral decisions. The discrepant rates of male and female HPV vaccination exemplify the negative effects of social categorization via gender in partnered health contexts.

\section{Theoretical Framework: Self-Categorization Theory}

According to self-categorization theory (Turner, 1987), an individual has multiple cognitive representations of his or her personal identity. Which cognitive representation is salient in a given interaction depends on the accessibility, value, importance, and fit of the category. A relevant category should sufficiently explain similarities and differences between social 
interactants as well as social interactants’ behaviors (Hogg \& Reid, 2006). Self-categorization occurs at three levels of abstraction. At the most abstract level, people categorize at the superordinate level contrasting humans with other species (Turner, 1987). At the intermediate level, people categorize via their social identity such that they define themselves according to similarities with ingroup members and distinctiveness from outgroup members (Turner, Oakes, Haslam, \& McGarty, 1994). At the subordinate level, people self-categorize based on unique characteristics that differentiate individuals from other ingroup members (Turner, 1987).

Shifting to a social identity built on contrasting one’s ingroup with a relevant outgroup has meaningful consequences for group members’ perceptions, attitudes, and behaviors. When social identity becomes salient, as it does through focus group discussions with similar others, people assume that they and others fit their group prototype, defined as "a set of features that best define a category” (Reid, Giles, \& Harwood, 2005, p. 246). People begin to see themselves less as unique individuals and more as "interchangeable representative[s] of a shared social category” (Turner et al., 1994, p. 455). A group member must also adhere to his or her perception of the group’s norms (Hogg \& Turner, 1987). Group norms are shared attitudes and behaviors among group members "that characterize a social group and differentiate it from other social groups” (Hogg \& Reid, 2006, p. 7).

Individuals who identify strongly with a social group are more likely to be influenced by perceived group norms (Terry \& Hogg, 1996). Gender is a readily accessible social identity that likely influences group norms regarding health care (see Mackie, Hamilton, Susskind, \& Rosselli, 1996). Generally, men value gender as a social identity more than women, as reflected in the greater importance they place in avoiding gender deviance and perceiving their sexuality as conforming to gender group norms (Clarke, Marks, \& Lykins, 2015; Sanchez, Crocker, \& 
Boike, 2005). Men also have been shown to be more accepting of stereotypical gender roles than women (de Lemus, Bukowski, Spears, \& Telga, 2015). Men who conform more strongly to traditional norms of masculinity and perceive other men as not engaging in health promotion behaviors perform fewer health behaviors themselves (Mahalik, Burns, \& Syzdek, 2007). Discourse shapes the norms and behaviors we expect from others and how we understand and evaluate others' behaviors.

Our goal in this report was to investigate the gender discourses produced in focus group discussions that college men recalled and activated to explain their behavior in the context of partnered health, particularly in understanding discrepant rates of male and female HPV vaccination. One broad question guided analysis:

RQ: What sexual health roles and responsibilities do college men perceive for college men and college women, particularly within the context of HPV prevention?

In answering this research question, we noticed participants’ heavy reliance on gender norms and discourses to explain perceptions of men's and women's sexual health roles and responsibilities. Self-categorization via social identity in partnered health contexts provides one explanation for men's reliance on gender norms to make sense of HPV prevention behaviors. By highlighting the norms and discourses heterosexual college men use to shape and understand their own and their sexual partners' responsibilities we hope to start a conversation about the often-unseen influence of gender on sexual health behaviors, especially preventative sexual health behaviors like HPV vaccination. We also hope to draw awareness to the impact of group identity on health behaviors and provide a possible mechanism to explain the gap between men's and women's preventive sexual health behaviors.

\section{Methods}




\section{Recruitment and Participants}

As part of a larger investigation on sexual health and HPV prevention among college men (see Authors, 2016), the principal investigator (PI) convened nine focus groups among 84 college men in January and February 2014. The study was approved for compliance with the University’s Institutional Review Board (IRB) for the protection of human participants. We recruited participants directly from Communication courses and indirectly through peer recruitment. Male students received a nominal amount of course credit to participate and to recruit an additional eligible man. Female students received equivalent course credit to recruit two eligible male participants.

Participants spoke English and ranged in age from 18-39 years $(M=21)$. Despite attempts to increase diversity within the sample through peer recruitment, a majority of participants identified as Caucasian (61\%) and heterosexual (95\%). Other participants identified as Hispanic (17\%), Black or African American (8\%), Asian (6\%), or “other” (8\%). Prior to the discussion, $49 \%$ of the students indicated they were unsure about their HPV vaccination status, $39 \%$ reported they were not vaccinated, and $12 \%$ reported having completed or initiated the vaccine series. Although the majority of participants indicated uncertainty about their HPV vaccination status at the outset, as they became aware of the dosing and age requirements for the vaccine they revealed with more certainty that they had not received the vaccine.

\section{Focus Group Method and Procedures}

Focus group discussions are ideally suited for the generation of messages representing group norms, in this case, college men’s perceptions of sexual health responsibility and behaviors. Focus group discussions are convened when researchers are interested in the shared thoughts, expressions, and behaviors of a targeted group (Rubin \& Rubin, 1995). Focus groups 
offer a forum to discuss matters of social importance through planned and guided discussions in a permissive, non-threatening environment (Krueger, 1994). Thus, although they are guided by specific prompts, discussions that emerge through focus groups are both spontaneous and synergetic. By examining the emergent discourse, scholars can gain unique insights about the dominant narratives and rationalities that underpin beliefs and behaviors of a particular group (see Lindegaard, 2014). Finally, because participants are asked to articulate their thoughts or experiences about a range of issues related to the core topic, focus group conversations may bring to bear beliefs, attitudes, and behaviors that are normally out-of-awareness for participants. Each focus group convened for two hours. Upon arrival, participants were encouraged to get to know each other through small talk and partake in the provided meal. A female undergraduate research assistant welcomed each participant and facilitated first-name introductions. When all of the participants had arrived, the assistant directed them toward their seats located around a large conference table indicated by nameplates. Each place setting had a pen, notepad, two copies of the informed consent document, and a double-sided HPV fact sheet from the CDC (2014). A white male graduate student trained in focus group interviewing served as the moderator. He led participants through the consent documents and informed them about the purposes and procedures of the study. The PI also attended the first five sessions to ensure quality of procedures and to debrief the participants and research team. The female assistant and PI receded unobtrusively to the back of the room to observe the interaction. While the presence of a female observer may be a concern in constraining participants' discourses we believe this was not the case here because a) of the apparent lack of constraint with which participants addressed sexual health beliefs, attitudes, and behaviors, b) the participants quickly oriented to and directed comments toward the male moderator, and c) when participants were asked during 
debriefing about the presence of a female observer at focus groups they were indifferent. For example, in response to the debriefing question about whether having women in the room influenced their responses and level of comfort 1P6 shared, "I think like women we know really well, would be awkward, since like I’m not familiar with you guys, I really don’t care.” To which 1P2 responded, “I feel the same way” and 1P1 added later "Like, personally, I could care less.”

The moderator guide included 12 core discussion areas and 19 prompts. First, participants were asked "what are the biggest concerns college-age males have about sexual and reproductive health, and why?” Participants were further prompted to consider positive and negative aspects of sexual health. Participants were then primed to think about college men and college women, “Do you think college-aged males and females are equally informed about sexual and reproductive health?” The prompts that followed included questions about roles, responsibility, and equity. Next, participants were asked specific questions about their level of awareness/knowledge about HPV and the HPV vaccine. Then, participants were directed to read the provided CDC fact sheet. After five minutes, the moderator gave a brief overview of the fact sheet and then prompted participants to discuss the information they learned from the fact sheet and their beliefs and attitudes about HPV prevention. The remaining questions focused only on college men. The prompts and moderation guide are available upon request. We reached data saturation after focus group seven. Saturation is a benchmark of trustworthiness in qualitative data collection that occurs when focus groups begin repeating threads of discourse already established in earlier groups (Rubin \& Rubin, 1995). We collected data beyond the point of saturation to allow all volunteers to participate and to facilitate greater discussion of HPV on the 
college campus where this research took place. Adding the final two focus groups also increased confirmability and dependability of interpretations (Lincoln \& Guba, 1985).

Focus groups were audio recorded and the research team transcribed each discussion verbatim. Transcript accuracy was enhanced through triangulation of three separate audio recordings and the session notes. Additionally, each transcript was reviewed for accuracy against the audio recordings by a member of the research team who did not prepare the initial transcription. During transcription, we de-identified participants by removing or changing information that might identify a participant or a group to which the participant belonged. Each participant was assigned a 2-unit code to help maintain participant confidentiality (i.e., 2P3 refers to focus group 2; participant 3).

\section{Data Analysis}

Data were organized for analysis with the assistance of N-Vivo, a qualitative data software program. Applying Saldaña’s (2013) notion of first- and second-cycle coding, the research team first engaged in collaborative open coding of the transcripts for phrases, statements, and interactive discourse that provided insight into college men's perceptions of responsibilities regarding sexual health. Collaborative coding involved working through the first two transcripts together, line-by-line, to discuss and assign unique tags to meaningful chunks of discourse. Collaborative coding helps to establish coding protocol and to enhance trustworthiness in qualitative data analysis through on-going negotiation and articulation of analytical decisions (see Lincoln \& Guba, 1985). Then, the research team divided the remaining transcripts and opencoded them independently. Open codes refer to free-standing codes assigned to units of data that capture the meaning of the discourse in a concise yet descriptive label. When possible, the research team used the participants' words as the code (i.e., an in-vivo code). Coding in-vivo 
phrases helps to ensure confirmability in qualitative data analysis (Lincoln \& Guba, 1985). Once the first round of open coding was completed, the research team met to review each code and discuss and negotiate the appropriateness of its fit and relevance in informing our research question.

Our second cycle coding approach involved reviewing open-codes for their similarities, distinctions, and relationships to each other and then clustering similar codes into increasingly larger categories. This involved examining open codes for their conceptual fit with other open codes and editing, expanding, and collapsing categories until all (or nearly all) of the open codes were accounted for in broader groups. Finally, we examined the relationships among categories in developing themes that re-present the data in a meaningful way. Themes are derived from, but also transcend, categories by weaving them together at a higher order of abstraction (DeSantis \& Ugarriza, 2000). We uncovered three broad themes: (1) an ideal of shared sexual responsibility, (2) the reality of unequal sexual health responsibility rationalized by gender discourses, and (3) a future where men guided by protection discourses take on greater sexual health responsibility.

\section{Results}

Emergent discourse demonstrated that college men view sexual health from a social identity standpoint that imposes behavioral norms. The perceived norms for men and women are created, shaped, and refined by gender discourses that rationalize discrepancies between their partnered health behaviors. Despite the strong influence of norms and gender discourse, college men identified an ideal situation where men and women share equal responsibility for sexual health. And yet, they recognized that in reality this was not the case. They invoked discourses that position college men as highly sexually active compared to women who are vulnerable to negative sex-related outcomes but also given greater opportunities to gain knowledge about 
sexual health. Projecting into the future, men viewed themselves as being able to take part in responsible partnered sexual health when they became fathers and husbands. These perceived norms have consequences for the roles and responsibilities men enact in HPV prevention.

\section{Ideal: Equal Responsibility for Sexual Health}

Participants recognized that in an “ideal world” (2P7) men and women would share sexual health responsibility. They thought, "everyone should be aware of their own reproductive health” (2P7), "both sexes should know of protection” (1P8), and sexual partners “should both be responsible...should (.) both be equally educated and know about these things” (5P9). They rationalized that sexual health should be “each individual person’s responsibility” (5P2) and sex is a "two person thing” (8P14). When asked what roles and responsibilities they believed college age women have for HPV prevention, 8P7 argued that “everyone’s fighting for equality for gender rights" and "if you [college women] want the same rights then you have to follow the same procedures” and “women as well as men need to be aware of what's going on.” 9P1 noted, “ideally, in a perfect world, it [sexual health] would just be the responsibility of everyone. If everyone took it as serious as maybe it really is then everyone would do whatever drastic measures they could and ultimately everyone would be protected.” Participants also argued that responsibility for HPV prevention should be equal for college men and women because "at the end of the day it's going to affect both people” (4P2), and negative health outcomes such as “cancer affects both male and female equally” (3P10). Some participants asserted that men should be equally as informed as women if “you don’t wanna ruin somebody’s life” (9P13). The notion that equal sexual responsibility could only occur in an "ideal world" or that people should take responsibility for their sexual health suggests that there are barriers, norms, and/or discourses that make equal sexual responsibility impossible or unlikely. 


\section{Reality: Inequality in Sexual Health}

Tension between the ideal of shared sexual health responsibility and the reality of unequal sexual health responsibility was evident in participant discourse. When asked whether sexual health responsibility is shared between men and women participants generally responded, “it should be but it’s not" (2P4). Similarly, 3P2 responded "I'd say we do [share equal sexual health responsibility] but we don't exercise it that way in reality in my experience.” Who in reality held greater sexual health responsibility was a point of contention. First noting, "in a perfect world everyone should" take equal responsibility, 9P1 went on to say that "girls are more obliged just ‘cause some guys don't feel as responsible.” 9P10 added that, "in a perfect world it would be fifty-fifty percent responsibility but I think guys have uhh, they should be more responsible with it because it's their dick, it's their problem.” Though 9P10 later added that for men "the worst case scenario is they get some disease sexually transmitted, but a girl could get pregnant if the guy forgets a condom...there's just so many more things that could go wrong with a girl.” Participants invoked a variety of discourses, detailed below, to explain inequalities. College male norms for sexual activity. College men perceived being highly sexually active yet dismissive about the consequences of sexual behavior as normative for their cohort. Participants described college men as "sleeping with or having more sexual activity" than college women (6P5). This behavior was rationalized as inherent in men who are "biologically wired to think more about sex than women are" (2P4) and "are animals... males just act to have sex" (2P6). Others contextualized sexual activity as normative on college campus regardless of gender. They described the college environment as a "huge playground to explore... a lot of different things sexually" (5P8) and that their college cohort is "probably more sexually active than the average American or human-being” (9P1). 
With regard to ambivalence toward sexual health, many participants felt that college men are "more willing to take the chances” (6P5) and "naturally we are more like 'I don't care, I’ll take my odds”” (6P6). Specifically, they perceived "less care on our end when it comes to any kind of STIs” (4P2). They reasoned, "males can just be more reckless with their sexual actions” (3P5) and portrayed themselves as opposite to perceived norms of college women who "think about their future a lot more" (2P5) and are "more mature at this point in their lives" (2P7).

College male concerns regarding sexual health. When participants were asked about their greatest concerns regarding sexual health two concerns dominated all groups: not to get a girl pregnant and to avoid STDs. The partnered aspect of pregnancy and the heightened responsibility of fatherhood seemed the most grievous outcomes to participants. 9P5 explained that "having a kid (.) uh not only puts a burden on you but, it can almost keep you stuck with, maybe, a girl that you don’t want to be stuck with for the rest of your life?” Focus group 3 participants felt that STDs were problematic but "unwanted kids is deeper than that” (3P4), “it kinda ties you with a woman too, which sucks” (3P5). 6P7 summarized many participants’ concerns when he said, “when you are single I wanna stay single and if you get a girl pregnant then that's gonna change the rest of your life.” Concerns about STDs were fewer but included concerns about telling partners, changes in their social lives, or partners misleading them about their health status.

Women are more vulnerable to negative outcomes. Despite their own pregnancy and STD concerns, participants perceived college women as more vulnerable to potential negative outcomes of sexual intercourse, especially unplanned pregnancy and social stigma. Although pregnancy emerged as the overwhelming concern for college men they recognized that women “are the ones that actually get pregnant and have to worry about the child” (1P8) or as 3P8 put it, 
women "would be stuck with the child.” The consequences of pregnancy were also perceived to be long term for women who will “ultimately assume the motherly responsibility” (3P1).

Despite perceiving that their college cohort was highly sexually active, participants still described sex as a social liability for women. They cited stereotypes that "if a girl is out there sleeping with a lot of guys she is a slut and is looked down upon by her friends” (6P7). 1P10 believed that from a young age women are "told that sex is bad and they're supposed to be careful and not be sluts and the media and you know everything tells them, 'don't be a slut.’” Many participants cited the role of media in perpetuating the idea that “it's okay for them [men] to have sex, that has a positive connotation” but "the word slut you know for a girl, that's very negative” (1P7). Furthermore, women were expected to be safer when having sex because "guys [are] always gonna come in, try to convince the girl to have unprotected sex because it feels better, it’s more fun” but "girls socially are expected to be more clean than males are” (2P4).

Women are better equipped to be responsible for sexual health. Despite depicting college women as being vulnerable to negative outcomes from sex, men believed women are better equipped to handle these vulnerabilities. The perception that women are highly vulnerable but also well-resourced led participants to conclude that women should in fact be more responsible for sexual health.

While participants recognized the discrepant norms constraining men and women's sexual activity, they also offered reasons why women are expected to be less sexual than men. They believed that women have a greater ability than men to “control sexual desire” (3P5) and “can learn about how to control the situation more than guys” (4P3). 8P7 positioned men as sexual chasers who "always pursue women” so it is “always their [women’s] choice to decline or 
not" meaning women have the responsibility to "be informed about the consequences or the troubles that they can get into with men.”

Participants believed that women are offered a greater amount of detailed information about sexual health from a variety of sources including parents and peers, the media, and physicians. The perception of women's greater access, as compared to men's access, to communication about sexual health emerged frequently as a rationale for women's greater sexual health responsibility. Overall, participants felt women are "exposed to more knowledge about stuff like that” (6P2) than men. Sources of information for women included parents who participants believed shared more information with their daughters than with their sons. Compared to fathers, participants felt mothers are "quicker to give information about that stuff to their daughters than dads are to their sons... it's like the dad is just like 'go get'em son'” (4P8). Similarly, 3P6 claimed, “my dad says, ‘just wrap it up’ [wear a condom]. My mom goes more in depth [in discussions] with what not to do with my sister.” 7P12 put a finer point on the gender discourse that distinguishes sexual health talks with men as opposed to women:

I think that when women are educated they are told, "these are the reasons why you need to be safe, xyz." As guys, we are approached as just like "wear a condom or don't have sex" we are given two options where girls have free range of options...they may not be as informed, or more informed but the approach is different the way we are educated.

Not only did participants perceive that women received more information from parents but they also perceived women as "willing to like sit down and have a serious heart to heart about what's going on" (3P1) and "more open to talking about [sexual health] with their friends and their peers” (1P8). 9P5 has "only heard my female friends talk about [sexual health]” and 9P1 agreed that sexual health was “something that you and your [male] friends wouldn’t talk about.” 
All of this resulted in some participants concluding that women should be more responsible for sexual health. Participants determined that primarily because of their vulnerability to pregnancy, women have been and should be "a little bit more adamant about paying attention” to sexual health information (3P8). 7P12 ascribed women’s perceived greater sexual health knowledge to his belief that women "have more of an investment when it comes to reproductive parts.” Participants also perceived women as more responsible because they had the tools that allowed them to be responsible including "birth control” (6P5) that is "way more readily available than male birth control” (7P4). Women were perceived as especially responsible for preventing HPV because "worse can happen to them” (9P8), "they are at higher risk” (9P2), and “cervical cancer probably will be more devastating to them” (9P5).

\section{Future: Men Take Responsibility as the Protectors of Their Wives and Children}

When the conversation shifted to a future-oriented outlook, college men considered taking on the relationally defined social identities of fathers and husbands. Participants voiced a protection narrative where they took on the hypothetical role of protector to vulnerable women whom they envisioned as their spouses and mothers of their children. While some participants stated that vaccinating is "not something that I would jump up and go do right now" (4P1) they considered future vaccination in order to "protect my wife someday" (4P4). Considering future relationships, men reasoned that vaccinating was their responsibility because transmitting HPV "to my wife and cause[ing] her to get that, that would feel really awful” (4P4). They were especially concerned that by transmitting HPV to their significant other, she would develop cervical cancer, which is “a great concern, even as a man, I think because (.) it, I don’t know if anyone has had a family member go through that, but you're going through it with them, you know?” (1P3). 8P7 took a more partnered approach in saying that men should encourage their 
female partners to be vaccinated against HPV because "they keep our name after we die, like, they raise our children so... make sure that our women are actually healthy and that we're not killing them from cervical cancer.”

The worry of transmitting HPV to their children through their female partner was also a concern cited by some participants. Participants thought it was important to "prevent your offspring from getting it [HPV]" and prevent a possible "chain of your offspring or your family like having this virus” (4P2). 6P5 believed vaccination was especially important in a faithful relationship so that one’s significant other does not become infected with HPV and then "pass that on to your child come time of birth.” $5 \mathrm{P} 8$ also traced the transmission through women saying men should “obviously not give it [HPV] to the mom and then your kid” but also citing that men should get the vaccine because "as we grow older, for those of us that have families, probably wanna be healthy to be there for our kids.” Notably, some participants felt it was too late to be vaccinated themselves but they would vaccinate their future children. $2 \mathrm{P} 4$ specifically felt vaccination was “pointless” for himself but he would vaccinate his son.

\section{Discussion}

Discussions revealed college men’s perceived group norms, shaped by gender discourses, regarding men and women's responsibility for sexual health. The reliance on norms in focus group discussions indicates a tendency toward social categorization in the context of partnered sexual health. Socially categorizing in such a context leads to reliance on perceived group norms to direct one’s own behavior and expectations of one’s partner. Participants’ perceived group norms lend insight into attitudes and behaviors toward HPV prevention but also provide troubling evidence that engaging in responsible sex may rely solely on the behaviors of female partners. Some participants recognized and denounced unequal sexual health responsibility as 
unfair. Indeed, norms shaped and reified by discourse constrain members of both sexes and likely limit the male role in sexual health. That participants recognized and denounced this perceived inequality might signal a positive shift toward a partnered view of sexual health responsibility.

Participants’ discourse portrayed college males as highly sexually active, yet uninformed, and so unable to take sexual health responsibility equal to women. Participants’ discourse aligns with understandings of how men demonstrate their belonging as hegemonic males: by denying their vulnerability, displaying sexual appetite, and embracing risk while at the same time avoiding perceived feminine traits like using health care (Courtenay, 1998, 2000). The case of HPV vaccination illustrates the influence of these gender discourses and norms on behavior. Previous research has shown that even for a private behavior like HPV vaccination, adolescent men aged 11-17 showed more willingness to get vaccinated if they perceived higher peer acceptance of the HPV vaccine (Reiter, McRee, Kadis, \& Brewer, 2011). Similarly, men aged 18-26 identified the concern that receiving the HPV vaccine may be "emasculating or embarrassing” because of the misperception that the HPV vaccine was only for women (Reiter, Oldach, Randle, \& Katz, 2014). Gender norms and discourses also influence health care providers (HCPs). Though most HCPs (66-80\%) would vaccinate men and women equally against HPV, the remaining HCPs show a preference for vaccinating women (Zimet \& Rosenthal, 2010). Provider preferences based on gender are compounded by the fact that men are more likely than women to have had no recent contact with a physician and the negative correlation between masculinity and use of instrumental coping strategies, like asking for information or advice (Courtenay, 2004; Feng \& Xiu, 2016). In order for men to enact preventive health behaviors, they must reject the perceived group norms of male gender and risk 
undermining their group member status as males (Courtenay, 2000). Overreliance on gender norms shuts out half of the population from seeking and receiving sexual health care.

In order to understand their own responsibilities for sexual health men relied heavily on their perceptions of women's responsibilities. While college men envisioned an ideal where male and female sexual health responsibilities were equal they recognized a different reality where females were more responsible. This unequal responsibility was rationalized in part by discourse that constructs women as more vulnerable to negative outcomes of sexual activity. These vulnerabilities, as well as greater knowledge and prescribed feminine traits (clean, responsible, motherly), were cited in part as reasons women should be more responsible. Gender norms that position women as the vulnerable gatekeepers of partnered health are not only visible in men's discourse but also in HPV vaccination practices. Many physicians who recommend HPV vaccination to men cite the need to protect women from getting cervical cancer as part of their recommendation (Weiss, Zimet, Rosenthal, Brenneman, \& Klein, 2010). While women certainly are vulnerable to negative sexual health outcomes their vulnerability is only part of the equation. College men in this study perceived women as having greater access than men to knowledge and resources to ensure their sexual health in the face of their vulnerabilities. One source of discrepant information was parents. Participants perceived mothers as more willing to discuss sexual health with daughters, and indeed research suggests that fathers experience more discomfort than mothers when discussing sexual health with their children (Ogle, Glasier, \& Riley, 2008). Compared to daughters, sons might be more negatively impacted by fathers’ discomfort with sexual health discussions. Such discrepancies in sexual health information mean that men are often not afforded the knowledge required to be fully accountable for their own sexual health, despite being vulnerable to negative sexual health outcomes. Instead, men’s 
vulnerability to negative sexual health outcomes and responsibilities for sexual health are often overlooked or dismissed.

Despite the discrepancies perpetuated by group norms, when participants considered intergenerational consequences they bought into a protection discourse which advocated responsible partnered health behavior. Protection discourses have been used in prior HPV vaccine interventions. For example, messages highlighting altruistic motives for HPV vaccination, specifically the benefits of the HPV vaccine for women and society, were more successful at increasing male HPV vaccine acceptance than those without altruistic motives (Bonafide \& Vanable, 2015). Many parents who decided to vaccinate their sons against HPV were influenced by concerns about protecting their sons’ future female partners (Schuler, DeSousa, \& Coyne-Beasley, 2014). College men themselves identify protecting current and future relational partners as a benefit of HPV vaccination (Authors, 2016). These findings provide hope that while men may not recognize or be equipped to advocate for their own sexual health vulnerabilities, they recognize vulnerability in relational others and are motivated to prevent negative sexual health outcomes for them. However, the desire to protect women who fill the conventional roles of "good" mother and wife signals benevolent sexism defined as gender-based evaluations that may appear subjectively positive but inhibit gender equality (Glick \& Fiske, 2001). We must therefore consider that the endorsement of protection discourses by college males may indicate a decreased likelihood of equality for sexual health responsibility in the future and may be cause for even greater concern among advocates for equal sexual health responsibility.

A different way to conceptualize equality of sexual health responsibility is to focus less on sex as a 'risky' behavior and take a sex-positive view. The concept of risk itself is subjective, 
socially constructed, and often politicized (Slovic, 1999). Though we do construct HPV and unprotected sex as 'risky' we also asked participants early in the discussion what their greatest sexual health concerns were, thereby giving them voice to explain their perceptions of sexual risk. Participants were also given space to consider sex positively, with the moderator asking whether participants wanted to identify "any benefits, any positives...not just things you want to avoid?” regarding sex. A sex-positive approach allows for a “wide range of sexual expression” that also accounts for the "pleasurable, rewarding, and non-procreative aspects of sex" (Williams, Prior, \& Wegner, 2013, p. 273). From a sex-positive perspective, as one reviewer noted, equalization of sexual health responsibility might entail men being more informed but still highly sexually active while women remain informed but perhaps less reserved or concerned about social repercussions resulting from their sexual actions.

The role of time and consideration of future consequences seem to have an especially strong influence on college men’s health behaviors. Time can be a barrier to male HPV vaccination when men perceive it is "too late" in terms of their age and sexual activity to be vaccinated, but they also perceive avoiding future regret as a benefit of vaccination (Authors, 2016). In fact, men with trait consideration of future consequences were more likely to perceive greater severity of HPV, fewer logistical and financial barriers to vaccination, and greater vaccine efficacy, all suggesting a greater likelihood of vaccination for these men (Kim \& Nan, 2015). Time can also influence gender identity. In looking back over their lives, men and women recognized times when they were more likely to behave gender normatively (e.g., during courtship and marriage) and times when they were more likely to engage in opposite-sex behaviors (e.g., when they were young or children had left the house) (Pearson \& VanHorn, 
2004). In the role of father and husband, men expect to behave gender normatively, which opens possibilities of engaging in preventive health behaviors to protect vulnerable others.

While hopeful, participants’ envisioning of greater future responsibility for sexual health is not enough. Men must be provided opportunities to fully take part in sexual health earlier in their lifespans. College males’ recognition of the tension between an ideal of shared sexual health responsibility and the reality of unequal sexual health responsibility provides an opportunity for messages to incite behavior change. Health messages that increase the magnitude of the existing tension may begin to equalize rates of male and female preventive behavior if the dissonance between ideal and real builds so that it can be resolved in no other way than behavior change. Other messages might encourage superordinate self-categorization in the context of partnered health behaviors in order to inspire sexual health partners to perceive each other as fundamentally similar human beings who should take the same actions toward sexual health. Still other messages might take a social norms approach aimed at resetting perceived norms to align more closely with actual norms. This method might be particularly fruitful given that this study captured college men's perceived norms regarding sex on college campuses and college students often overestimate their peers' level of sexual activity and occurrence of sexually transmitted infections, while underestimating the prevalence of condom use (Scholly, Katz, Gascoigne, \& Holck, 2005; Martens et al., 2006). Rather than reproducing messages that lead to social categorization in partnered health contexts, message creators have the opportunity to include all sexually active adults regardless of gender in discourse about responsible sexual health.

One strength of this study was our ability to examine norms through group discussions where we believe male sexual identity in the context of HPV prevention was salient. Group discussions were led by a white college male and consisted of college men who overwhelmingly 
identified as white and heterosexual. Hogg and Reid (2006) suggest that people are better able to infer attitudinal norms when the group is highly salient and members identify strong with the group. If this is the case, our focus group analysis likely did uncover group norms and prevalent discourses because the groups were relatively homogenous and shared characteristics of the group were made clear through discussion. Furthermore, focus group participants often evoked a sense of "we" as college males in the discussion, referring to themselves as "we at this table" and asserting that "probably none of us have..." We are limited however, in the extent to which we can claim that participants perceived themselves to be members of a shared social group because we did not explicitly examine the extent to which participants perceived the moderator and other group members to be representative of their shared social category.

Focus group discussions offer understanding for researchers and an additional positive outcome for participants. Through discussion participants can enhance their own knowledge on a topic as well as increase their communication self-efficacy (Zorn, Roper, Broadfoot, \& Weaver, 2006). Following each focus group, we answered participants’ HPV-related questions and distributed information packets from the CDC and Campus Health. Equipped with relevant and accurate information, participants may find opportunities to discuss HPV prevention with others in their social network. Indeed, several participants noted that peer-recruitment provided the first chance to consider HPV vaccination for college men. Although small, the ripples of communication that started with the peer-recruitment strategy and continued throughout the group discussions may continue to gain force beyond the bounds of this research project.

\section{Limitations}

Although focus group discussions captured dominant cultural discourses, in order to understand the norms constraining young adult males' full participation in sexual health it is 
necessary to include men who represent different ages, cultures, and sexual orientations.

Previous HPV-related research suggests, for example, that men with higher education, Hispanic males, and gay/bisexual males have higher vaccine acceptability (Ferris et al., 2009; Reiter et al., 2010), and Black males are more interested in learning about the HPV vaccine than other males (Gerend \& Magloire, 2008). Finally, as one reviewer noted, our research question established an inherent division between men and women. Together, the research question and prompts may have primed participants to think about their role in contrast to that of women. Future research that allows research participants to negotiate health roles in their relationships without direction as to a male/female focus would be useful.

\section{Conclusion}

The findings from this study highlight college men's reliance on gender discourses that rationalize discrepant sexual health responsibility between men and women. Their reliance on gender discourses and norms to explain partnered health behavior suggest self-categorization as a mechanism influencing this cohort's sexual health. Males simultaneously bought into gender discourses yet were frustrated by the inequality and lack of serious consideration societally for their own responsibility, and lack of resources. While the gender discourses invoked by males place primary responsibility for sexual health on females, their recognition of an ideal shared sexual responsibility and envisioning of greater responsibility as fathers and husbands are somewhat positive findings, though tempered by concerns of benevolent sexism. Future interventions highlighting actual norms and encouraging superordinate self-categorization during partnered behaviors and subsequently lesser reliance on gender norms to predict sexual health behaviors may be useful in bringing about a sense of shared responsibility for sexual health resulting in more preventative behaviors such as HPV vaccination. 


\section{References}

Bonafide, K. E., \& Vanable, P. A. (2015). Male human papillomavirus vaccine acceptance is enhanced by a brief intervention that emphasizes both male-specific vaccine benefits and altruistic motives. Sexually Transmitted Diseases, 42, 76-80.

doi:10.1097/OLQ.0000000000000226

Centers for Disease Control and Prevention (2011a). Recommendations on the use of quadrivalent human papillomavirus vaccine in males - Advisory Committee on Immunization Practices (ACIP), 2011. Morbidity and Mortality Weekly Report, 60, 17051708.

Centers for Disease Control and Prevention (2011b). National and state vaccination coverage among adolescents aged 13-17 Years — United States, 2010. Morbidity and Mortality Weekly Report, 60, 1117-1123.

Centers for Disease Control and Prevention (2014). Genital HPV infection - Fact sheet. Retrieved from http://www.cdc.gov/std/hpv/hpv-factsheet-march-2014.pdf

Centers for Disease Control and Prevention (2016a). Genital HPV infection - Fact sheet. Retrieved from http://www.cdc.gov/std/hpv/stdfact-hpv.htm

Centers for Disease Control and Prevention (2016b). National, regional, state, and selected local area vaccination coverage among adolescents aged 13-17 years — United States, 2015. Morbidity and Mortality Weekly Report, 65, 850-858.

doi:http://dx.doi.org/10.15585/mmwr.mm6533a4

Clarke, M. J., Marks, A. G., \& Lykins, A. D. (2015). Effects of gender group norms on the endorsement of same-sex attraction, behavior, and identity. Journal of Bisexuality, 15, 319-345. doi:10.1080/15299716.2015.1050537 
Courtenay, W. H. (1998). College men’s health: An overview and a call to action. Journal of American College Health, 46, 279-290. doi:10.1080/07448489809596004

Courtenay, W. H. (2000). Constructions of masculinity and their influence on men’s well-being: A theory of gender and health. Social Science \& Medicine, 50, 1385-1401. doi:10.1016/S0277-9536(99)00390-1

Courtenay, W. H. (2004). Best practices for improving college men’s health. New Directions for Student Services, 107, 59-74. doi:10.1002/ss.133

de Lemus, S., Bukowski, M., Spears, R., \& Telga, M. (2015). Reactance to (or acceptance of) stereotypes: Implicit and explicit responses to group identity threat. Zeitschrift Für Psychologie, 223, 236-246. doi:10.1027/2151-2604/a000225

DeSantis, L., \& Ugarriza, D. N. (2000). The concept of theme as used in qualitative nursing research. Western Journal of Nursing Research, 22, 351-372. doi:10.1177/019394590002200308

Dryzek, J.S. (2006). Deliberative global politics: Discourse and democracy in a divided world. Cambridge, UK: Polity Press.

Feng, H., \& Xiu, L. (2016). The effects of sex and gender role orientation on approach-based coping strategies across cultures: A moderated mediation model. Communication Quarterly, 64, 596-622. doi:10.1080/01463373.2016.1176940

Ferris, D. G., Waller, J. L., Miller, J., Patel, P., Price, G. A., Jackson, L., \& Wilson, C. (2009). Variables associated with human papillomavirus (HPV) vaccine acceptance by men. Journal of the American Board of Family Medicine, 22, 34-42. doi:10.3122/jabfm.2009.01.080008. 
Gerend, M. A., \& Magloire, Z. F. (2008). Awareness, knowledge, and beliefs about human papillomavirus in a racially diverse sample of young adults. Journal of Adolescent Health, 42, 237-242. doi:10.1016/j.jadohealth.2007.08.022

Gilbert, P., Brewer, N. T., Reiter, P. L., Ng, T. W., \& Smith, J. S. (2011). HPV vaccine acceptability in heterosexual, gay, and bisexual men. American Journal of Men’s Health, 5, 297-305. doi:10.1177/1557988310372802.

Glick, P., \& Fiske, S. T. (2001). An ambivalent alliance: Hostile and benevolent sexism as complementary justifications for gender inequality. American Psychologist, 56, 109-118. doi:10.1037//0003-066X.56.2.109

Haslam, S. A., Jetten, J., Postmes, T., \& Haslam, C. (2009). Social identity, health and wellbeing: An emerging agenda for applied psychology. Applied Psychology: An International Review, 58, 1-23. doi:10.1111/j.1464-0597.2008.00379.x

Heather, H. J., \& Murphy, S. T. (2010). Sex roles in health storylines on prime time television: A content analysis. Sex Roles, 62, 810-821. doi:10.1007/s11199-009-9654-0

Hogg, M. A., \& Reid, S. A. (2006). Social identity, self-categorization, and the communication of group norms. Communication Theory, 16, 7-30. doi:10.1111/j.14682885.2006.00003.x

Hogg, M. A., \& Turner, J. C. (1987). Intergroup behaviour, self-stereotyping and the salience of social categories. British Journal of Social Psychology, 26, 325-340. doi:10.1111/j.20448309.1987.tb00795.x

Hust, S. T., Brown, J. D., \& L’Engle, K. L. (2008). Boys will be boys and girls better be prepared: An analysis of the rare sexual health messages in young adolescents' media. Mass Communication \& Society, 11, 3-23. doi:10.1080/15205430701668139 
Kim, J., \& Nan, X. (2015). Consideration of future consequences and HPV vaccine uptake among young adults. Journal of Health Communication, 20, 1033-1040. doi:10.1080/10810730.2015.1018583

Krueger, R. A. (1994). Focus groups: A practical guide for applied research ( $2^{\text {nd }}$ ed.). Thousand Oaks, CA: Sage.

Lincoln, Y. S., \& Guba, E. G. (1985). Naturalistic inquiry. Beverly Hills, CA: Sage.

Lindegaard, L. B. (2014). Doing focus group research: Studying rational ordering in focus group interaction. Discourse Studies, 16, 629-644. doi:10.1177/1461445614538563

Mackie, D. M., Hamilton, D. L., Susskind, J., \& Rosselli, F. (1996). Social psychological foundations of stereotype formation. In C. N. Macrae, C. Stangor, \& M. Hewstone (Eds.), Stereotypes and stereotyping, (pp. 41-78). New York, NY: The Guilford Press.

Mahalik, J. R., Burns, S. M., \& Syzdek, M. (2007). Masculinity and perceived normative health behaviors as predictors of men’s health behaviors. Social Science \& Medicine, 64, 22012209. doi:10.1016/j.socscimed.2007.02.035

Malkowski, J. (2014). Confessions of a pharmaceutical company: Voice, narrative, and gender dialectics in the case of Gardasil. Health Communication, 29, 81-92. doi:10.1080/10410236.2012.719178

Martens, M. P., Page, J. C., Mowry, E. S., Damann, K. M., Taylor, K. K., \& Cimini, M. D. (2006). Differences between actual and perceived student norms: An examination of alcohol use, drug use, and sexual behavior. Journal of American College Health, 54, 295300. doi:10.3200/JACH.54.5.295-300 
Ogle, S., Glasier, A., \& Riley, S. C. (2008). Communication between parents and their children about sexual health. Contraception, 77, 283-288. doi:10.1016/j.contraception.2007.12.003

Palefsky, J. M. (2010). Human papillomavirus-related disease in men: Not just a women’s issue. Journal of Adolescent Health, 46, S12-S19. doi:10.1016/j.jadohealth.2010.01.010

Pearson, J. C., \& VanHorn, S. B. (2004). Communication and gender identity: A retrospective analysis. Communication Quarterly, 52, 284-299. doi:10.1080/01463370409370198

Reid, S. A., Giles, H., \& Harwood, J. (2005). Chapter 11: A self-categorization perspective on communication and intergroup relations. In J. Harwood, \& H. Giles (Eds.), Intergroup Communication, (pp. 241-263). New York, NY: Peter Lang.

Reiter, P. L., McRee, A. L., Kadis, J. A., \& Brewer, N. T. (2011). HPV vaccine and adolescent males. Vaccine, 29, 5595-5602. doi:10.1016/j.vaccine.2011.06.020

Reiter, P. L., Oldach, B. R., Randle, K. E., \& Katz, M. L. (2014). Acceptability of HPV vaccine for males and preferences for future education programs among Appalachian residents. American Journal of Men’s Health, 8, 167-174. doi:10.1177/1557988313505319

Reiter, P. L., Pendergraft, W. F., \& Brewer, N. T. (2010). Meta-analysis of human papillomavirus infection concordance. Cancer Epidemiology Biomarkers \& Prevention, 19, 2916-2931. doi:10.1158/1055-9965.EPI-10-0576

Rubin, H. J., \& Rubin, I. S. (1995) Qualitative interviewing: The art of hearing data. Thousand Oaks, CA: Sage Publications.

Saldaña, J. (2013). The coding manual for qualitative researchers ( ${ }^{\text {nd }}$ ed.). Los Angeles, CA: Sage. 
Sanchez, D. T., Crocker, J., \& Boike, K. R. (2005). Doing gender in the bedroom: Investing in gender norms and the sexual experience. Personality and Social Psychology Bulletin, 31, 1445-1455. doi:10.1177/0146167205277333

Scholly, K., Katz, A. R., Gascoigne, J., \& Holck, P. S. (2005). Using social norms theory to explain perceptions and sexual health behaviors of undergraduate college students: An exploratory study. Journal of American College Health, 53, 159-166.

doi:10.3200/JACH.53.4.159-166

Schuler, C. L., DeSousa, N. S., Coyne-Beasley, T. (2014). Parents’ decisions about HPV vaccine for sons: The importance of protecting sons’ future female partners. Journal of Community Health, 39, 842-848. doi:10.1007/s10900-014-9859-1

Slovic, P. (1999). Trust, emotion, sex, politics, and science: Surveying the risk-assessment battlefield. Risk Analysis, 19, 689-701. doi:10.1111/j.1539-6924.1999.tb00439.x

Terry, D. J., \& Hogg, M. A. (1996). Group norms and the attitude-behavior relationship: A role for group identification. Personality and Social Psychology Bulletin, 22, 776-793. doi:10.1177/0146167296228002

Tetreault, P. A., Fette, R., Meidlinger, P. C., \& Hope, D. (2013). Perceptions of campus climate by sexual minorities. Journal of Homosexuality, 60, 947-964. doi:10.1080/00918369.2013.774874

Thompson, M. (2010). Who’s guarding what? A poststructural feminist analysis of Gardasil discourses. Health Communication, 25, 119-130. doi:10.1080/10410230903544910

Tolman, D. L., Davis, B. R., \& Bowman, C. P. (2016). 'That’s just how it is': A gender analysis of masculinity and femininity ideologies in adolescent girls’ and boys’ heterosexual relationships. Journal of Adolescent Research, 31, 3-31. doi:10.1177/0743558415587325 
Turner, J. C. (1987). A self-categorization theory. In J. C. Turner, M. A. Hogg, P. J. Oakes, S. D. Reicher, \& M. S. Wetherell (Eds.), Rediscovering the social group: A self-categorization theory (pp.42-67). Oxford, UK: Basil Blackwell.

Turner, J. C., Oakes, P. J., Haslam, S. A., \& McGarty, C. (1994). Self and collective: Cognition and social context. Personality and Social Psychology Bulletin, 20, 454-463. doi:10.1177/0146167294205002

Weiss, T. W., Zimet, G. D., Rosenthal, S. L., Brenneman, S. K., \& Klein, J. D. (2010). Human papillomavirus vaccination of males: Attitudes and perceptions of physicians who vaccinate females. Journal of Adolescent Health, 47, 3-11. doi:10.1016/j.jadohealth.2010.03.003

Wickens, C. M., \& Sandlin, J. A. (2010). Homophobia and heterosexism in a college of education: A culture of fear, a culture of silence. International Journal of Qualitative Studies in Education, 23, 651-670. doi:10.1080/09518390903551035

Williams, D. J., Prior, E., \& Wegner, J. (2013). Resolving social problems associated with sexuality: Can a 'sex-positive' approach help? Social Work, 58, 273-275 doi:10.1093/sw/swt024

Zimet, G. D., \& Rosenthal, S. L. (2010). HPV vaccine and males: Issues and challenges. Gynecologic Oncology, 117, S26-S31. doi:10.1016/j.ygyno.2010.01.028

Zorn, T. E., Roper, J., Broadfoot, K., \& Weaver, C. K. (2006). Focus groups as sites of influential interaction: Building communicative self-efficacy and effecting attitudinal change in discussing controversial topics. Journal of Applied Communication Research, 34, 115-140. doi:10.1080/00909880600573965 